\title{
Predicting the Occurrence of Oxygenation Impairment in Patients with Type-B Acute Aortic Dissection
}

\author{
Kazunori Tomita, $\mathrm{MD}^{1} \quad$ Noritake Hata, MD, $\mathrm{PhD}^{1} \quad$ Nobuaki Kobayashi, MD, $\mathrm{PhD}^{1}$ \\ Takuro Shinada, MD, $\mathrm{PhD}^{1}$ Akihiro Shirakabe, MD, $\mathrm{PhD}^{1}$ \\ ${ }^{1}$ Intensive Care Unit, Chiba Hokusoh Hospital, Nippon Medical School, \\ Chiba, Japan \\ Address for correspondence Noritake Hata, MD, PhD, Intensive Care \\ Unit, Chiba Hokusoh Hospital, Nippon Medical School, 1715 Kamagari, \\ Int J Angiol 2014;23:53-60. \\ Inzai, Chiba, Japan 270-1694 (e-mail: hata-n@nms.ac.jp).
}

\begin{abstract}
Keywords

- acute aortic dissection

- inflammation

- oxygenation impairment

- prediction

Complicated respiratory failure requiring mechanical ventilation in patients with type-B acute aortic dissection (AAD) has been previously reported, and inflammatory reactions have been found to be associated with the occurrence of oxygenation impairment (OI). However, the possibility of predicting the occurrence of Ol in patients with type-B AAD has not yet been evaluated. This study was performed to investigate the possibility of predicting the occurrence of $\mathrm{Ol}$ in type-B AAD. In this study, 79 type-B AAD patients were enrolled to investigate the possibility of predicting the occurrence of OI. Ol was defined as $\mathrm{PO}_{2} / \mathrm{FlO}_{2} \leq 200$. Patient characteristics, type of $A A D$, vital signs on admission, and the presence of inflammatory reactions obtained on admission day were evaluated. Ol occurred in 39 patients (49\%) on hospital day $2.5 \pm 1.4$ on average. Younger age, male gender, nonslender frame (body mass index $\geq 22 \mathrm{~kg} / \mathrm{m}^{2}$ ), a relatively high maximum body temperature on the admission day $\left(\geq 36.5^{\circ} \mathrm{C}\right)$, DeBakey IIIb type, patent false lumen, and lower $\mathrm{PO}_{2} / \mathrm{FlO}_{2}$ on admission were found to be associated with the occurrence of OI. Multivariate analysis revealed that nonslender frame, relatively high body temperature on the admission day, and lower $\mathrm{Po}_{2} / \mathrm{FlO}_{2}$ on admission were reliable for predicting the occurrence of oxygen impairment. The occurrence of $\mathrm{Ol}$ in type-B AAD can be predicted in the clinical setting.
\end{abstract}

Acute aortic dissection (ADD) is a life-threatening cardiovascular disease that is frequently complicated by systemic disorders. The outcomes of patients with type-B AAD ${ }^{1}$ are better than those of patients with type-A AAD, ${ }^{2-4}$ although multiple organ failure, including respiratory failure requiring mechanical ventilation, has been reported. ${ }^{5-10}$ Although previous investigators have reported that oxygenation impairment (OI) is associated with systemic inflammatory reactions and distension of aortic dissections, ${ }^{5,6,10-13}$ the possibility of predicting the occurrence of $\mathrm{OI}$ in patients with type-B AAD has not been investigated because they stated that there was relationship between OI and peak values of inflammation during hospitalization. Therefore, we retrospectively evaluated factors associated with the occurrence of OI in type-B AAD patients and investigated the possibility of predicting the occurrence of OI during the acute phase of AAD for the prevention and management of respiratory distress.

\section{Method}

This study was conducted in accordance with the ethical standards of the Declaration of Helsinki, and the Institutional Ethics Review Board (Ethics Review Board of Chiba Hokusoh Hospital, Nippon Medical School) approved the study protocol (approval number 319). All data were retrospectively collected from medical records. Therefore, written informed consent was not required by the ethics review board, and the 
concept of the study was disclosed on a poster displayed in the institute. No financial support was received for this study, and there are no conflicts of interest to declare.

\section{Study Population}

In this study, 93 consecutive patients with type-B AAD admitted to the intensive care unit of the university hospital between January 2000 and November 2011 were enrolled. Eight patients were excluded due to emergency surgery, late admission (more than 24 hours after the onset of symptoms), or inadequate medical records. Patients with OI due to pneumonia (five patients) and heart failure (one patient) were also excluded. Therefore, the final study population included 79 type-B AAD patients (mean age: $66.8 \pm 12.9$ years, 52 males and 27 females).

\section{Evaluation of Clinical Findings and Diagnosis}

Data regarding patient backgrounds, clinical findings, and inhospital outcomes were retrospectively collected from the patients' medical records. The patient background data included age, gender, body height, body weight, body mass index, past medical history and habit, and the time from the onset of symptom to hospital admission. Vital signs (blood pressure, heart rate, and body temperature) and laboratory findings, including white blood cell (WBC) counts, the serum C-reactive protein (CRP) and creatinine levels, and findings of arterial blood gas analyses, obtained during intensive care were investigated. The arterial blood gas levels were measured using an automatic blood gas analyzer system (ABL 700, Radiometer, Copenhagen, Denmark). The oxygenation index was calculated according to the $\mathrm{PO}_{2} / \mathrm{FiO}_{2}$ ratio ( $\mathrm{P} / \mathrm{F}$ ratio), and the estimated $\mathrm{FiO}_{2}$ level was adopted as the $\mathrm{FiO}_{2}$ value in patients not receiving mechanical ventilation support. ${ }^{14} \mathrm{OI}$ was defined as a $\mathrm{P} / \mathrm{F}$ ratio $\leq 200$ during intensive manage- ment. ${ }^{15}$ In addition, the study patients were divided into two groups: those with (OI group) and those without (non-OI group) OI during intensive care.

The diagnosis of type-B AAD was made based on the results of contrast medium-enhanced computed tomography (CT). The type of AAD was classified according to the degree of involvement of the abdominal aorta (DeBakey IIIa or IIIb) ${ }^{16}$ and the presence of thrombosed false lumens or patent false lumens, including partial thrombosis. ${ }^{17}$

Factors affecting the occurrence of OI were evaluated, and findings obtained on the admission day were used as predictive factors.

\section{Statistical Analysis}

All continuous data are expressed as the mean \pm standard deviation, and mean differences between groups were analyzed using Student $t$-test. Proportional differences were analyzed using Fisher exact test. Categorical variables were analyzed using $\mathrm{X}^{2}$ test. A univariate analysis was used to evaluate factors predicting the occurrence of OI. In addition, cutoff values for factors associated with the occurrence of OI and prediction scores were calculated from receiver operating characteristic (ROC) curves. A multivariate logistic regression model was also used to evaluate factors associated with the occurrence of OI. A $p$ value $<0.05$ was considered to be statistically significant. All data were analyzed using the StatView 5 software package for Windows (SAS Institute, Cary, NC) and SPSS $14.0 \mathrm{~J}$ for Windows (SPSS Japan Institute, Tokyo, Japan).

\section{Results}

OI occurred in 39 of 79 type-B AAD patients (49.4\%) on hospital day $2.5 \pm 1.4$ on average (-Fig. 1 ).

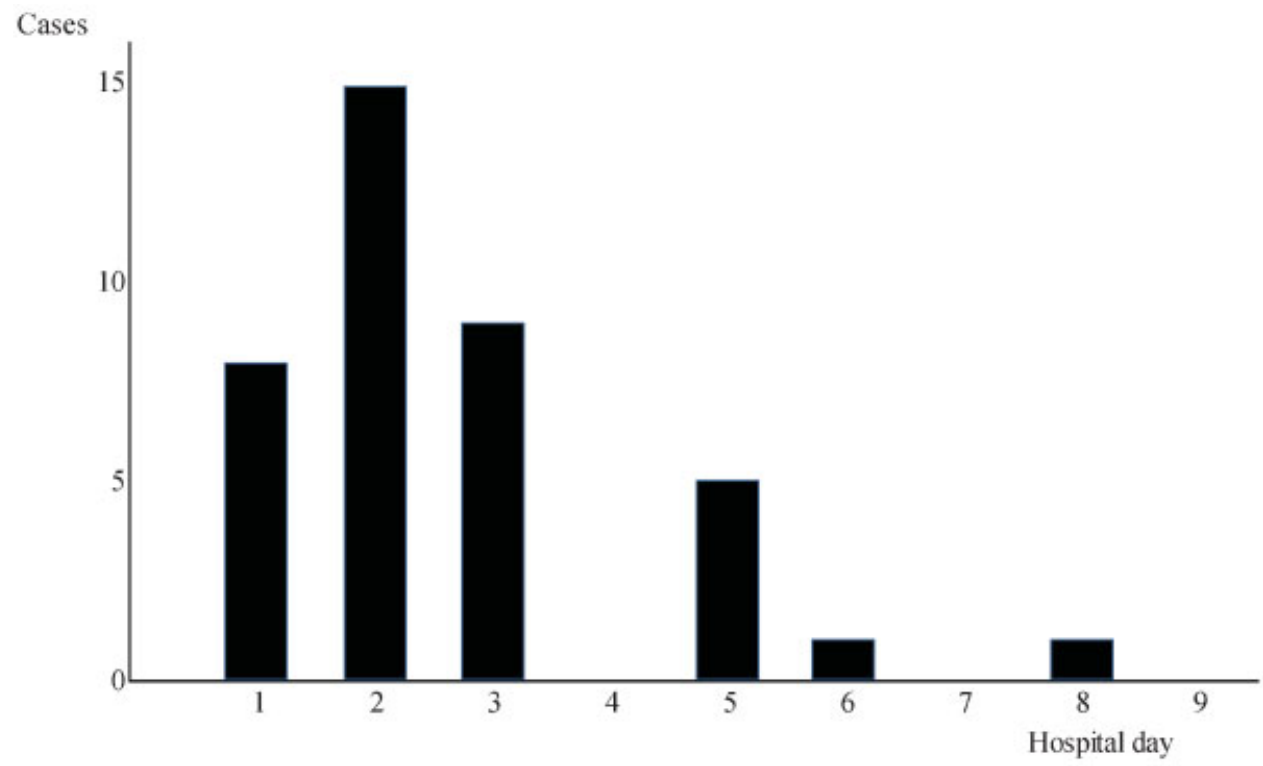

Fig. 1 Occurrence of oxygenation impairment after the onset of type-B acute aortic dissection. 
Table 1 Background of patients and clinical findings on admission

\begin{tabular}{|c|c|c|c|c|}
\hline & Total & Ol group & Non-Ol group & \multirow[t]{2}{*}{$p$ value } \\
\hline & $n=79$ & $n=39$ & $n=40$ & \\
\hline Age (years) & $66.8 \pm 12.9$ & $63.6 \pm 12.7$ & $69.9 \pm 12.4$ & 0.0281 \\
\hline Gender (male/female) & $52 / 27$ & $30 / 9$ & $22 / 18$ & 0.0135 \\
\hline \multicolumn{5}{|l|}{ Medical history } \\
\hline Hypertension (yes/no) & $72 / 7$ & $37 / 2$ & $35 / 5$ & 0.2490 \\
\hline Diabetes mellitus (yes/no) & $6 / 73$ & $3 / 36$ & $3 / 37$ & 0.9743 \\
\hline Dyslipidemia (yes/no) & $29 / 50$ & $17 / 22$ & $12 / 28$ & 0.2103 \\
\hline COPD (yes/no) & $4 / 75$ & $2 / 37$ & $2 / 38$ & 0.9793 \\
\hline Smoking (yes/no) & $58 / 21$ & $32 / 7$ & $26 / 14$ & 0.0863 \\
\hline Body mass index & $24.3 \pm 4.0$ & $25.6 \pm 4.0$ & $23.0 \pm 3.6$ & 0.0025 \\
\hline \multicolumn{5}{|l|}{ Vital signs on admission } \\
\hline Systolic blood pressure $(\mathrm{mm} \mathrm{Hg})$ & $175.0 \pm 34.4$ & $181.5 \pm 29.7$ & $168.6 \pm 37.8$ & 0.0953 \\
\hline Diastolic blood pressure $(\mathrm{mm} \mathrm{Hg})$ & $92.0 \pm 19.9$ & $95.6 \pm 20.2$ & $88.4 \pm 19.2$ & 0.1052 \\
\hline Body temperature $\left({ }^{\circ} \mathrm{C}\right)$ & $36.2 \pm 0.6$ & $36.2 \pm 0.7$ & $36.2 \pm 0.6$ & 0.5535 \\
\hline Time from onset to admission (hours) & $3.2 \pm 3.8$ & $2.7 \pm 3.7$ & $3.7 \pm 3.9$ & 0.2056 \\
\hline Serum creatinine (mg/dL) & $0.96 \pm 0.43$ & $0.94 \pm 0.46$ & $0.98 \pm 0.42$ & 0.6863 \\
\hline $\mathrm{Po}_{2} / \mathrm{FlO}_{2}$ on admission & $305.2 \pm 97.7$ & $253.5 \pm 85.4$ & $355.6 \pm 81.9$ & $<0.0001$ \\
\hline \multicolumn{5}{|l|}{ Type of aortic dissection } \\
\hline DeBakey (IIla/IIIb) & $13 / 66$ & $3 / 36$ & $10 / 30$ & 0.0381 \\
\hline False lumen (thrombosed/patent) & $47 / 32$ & $18 / 21$ & $29 / 11$ & 0.0171 \\
\hline
\end{tabular}

Abbreviations: COPD, chronic obstructive pulmonary disease; OI, oxygenation impairment.

\section{Patients' Backgrounds and Types of AAD}

The backgrounds of the patients and the clinical findings obtained on admission, including the type of AAD (DeBakey classification and the patency of false lumens), are shown in -Table 1. The patients in the OI group were younger $(63.6 \pm 12.7$ years $)$, larger body mass index $(24.3 \pm 4.0 \mathrm{~kg} /$ $\mathrm{m}^{2}$ ) and included more males (30 males, 77\%) than the patients in the non-OI group $(69.9 \pm 12.4$ years; body mass index: $23.0 \pm 3.6 \mathrm{~kg} / \mathrm{m}^{2} ; 22$ males, $55 \%$ ).

AAD type DeBakey IIIb (92.3\%) and the presence of patent false lumens (53.8\%) were more frequently seen in the OI group than non-OI group (75.0 and $27.5 \%$, respectively). However, there were no differences in vital signs on admission and the time from the onset of symptom to hospital admission between the two groups. No patient fell to shock vital requiring additional treatment after admission. $\mathrm{P} / \mathrm{F}$ ratio on admission was significantly lower in the OI group $(253.5 \pm 85.4)$ than non-OI group $(355.6 \pm 81.9)$.

Oxygenation Impairment and Inflammatory Reactions The inflammatory factors affecting the occurrence of $\mathrm{OI}$ in the type-B AAD patients during intensive care are shown in -Table 2. The WBC counts after hospital day 2 and the serum levels of CRP after hospital day 3 were higher in the OI group, however, there were no differences on the admission day. Furthermore, the maximum body temperature was higher in the OI group than non-OI group only on the admission day. OI was found on admission in six patients, in whom only the WBC count was less $(6,557 \pm 3,594 / \mu \mathrm{L})$ than those without OI on admission $(9,881 \pm 2,925 / \mu \mathrm{L})$.

\section{Predicting the Occurrence of Oxygenation Impairment} As OI occurred on hospital day 2.5 on average, seven factors obtained on admission day (younger age, male gender, nonslender frame, DeBakey IIIb, patent false lumen, relatively high maximum body temperature on the admission day, and low $\mathrm{P} /$ $\mathrm{F}$ ratio on admission) were investigated for their ability to predict the occurrence of OI after the onset of type-B AAD. The cutoff levels were determined using ROC curves according to age ( $<68$ years), nonslender frame (BMI $\geq 22 \mathrm{~kg} / \mathrm{m}^{2}$ ), relatively high maximum body temperature on the admission day $\left(>36.5^{\circ} \mathrm{C}\right)$, and low $\mathrm{P} / \mathrm{F}$ ratio on admission $(<300)$. These seven factors were found to be significantly associated with the occurrence of $\mathrm{OI}$ in a univariate analysis (-Table 3). Using a multivariate logistic regression model, nonslender frame, relatively high maximum body temperature on the admission day, and low $\mathrm{P} / \mathrm{F}$ ratio on admission were found to be independently associated with the occurrence of OI (-Table 4).

-Fig. 2 demonstrates the predictive power for the occurrence of $\mathrm{OI}$ after AAD. The scores, defined as the number of applicable factors, including nonslender frame (BMI $\geq 22 \mathrm{~kg} /$ $\mathrm{m}^{2}$ ), relatively high maximum body temperature on the admission day $\left(>36.5^{\circ} \mathrm{C}\right.$ ), and lower $\mathrm{P} / \mathrm{F}$ ratio on admission $(<300)$, were able to predict the occurrence of OI when the 
Table 2 Inflammatory reactions

\begin{tabular}{|c|c|c|c|}
\hline & OI group & Non-OI group & \multirow[t]{2}{*}{$p$ value } \\
\hline & $n=39$ & $n=40$ & \\
\hline \multicolumn{4}{|l|}{ WBC $(/ \mu \mathrm{L})$} \\
\hline Day 1 & $9,788 \pm 3,290$ & $9,472 \pm 2,902$ & 0.6510 \\
\hline Day 2 & $11,674 \pm 3,040$ & $8,966 \pm 2,568$ & $<0.0001$ \\
\hline Day 3 & $11,481 \pm 3,009$ & $9,210 \pm 2,438$ & 0.0004 \\
\hline Day 4 & $10,706 \pm 2,895$ & $8,786 \pm 2,091$ & 0.0014 \\
\hline Day 5 & $9,328 \pm 2,141$ & $8,088 \pm 2,211$ & 0.0201 \\
\hline Maximum & $12,865 \pm 2,934$ & $10,785 \pm 3,382$ & 0.0046 \\
\hline \multicolumn{4}{|l|}{ CRP (mg/dL) } \\
\hline Day 1 & $0.50 \pm 1.04$ & $0.42 \pm 0.67$ & 0.6734 \\
\hline Day 2 & $3.77 \pm 3.18$ & $3.00 \pm 2.35$ & 0.2252 \\
\hline Day 3 & $12.33 \pm 4.21$ & $9.22 \pm 4.26$ & 0.0017 \\
\hline Day 4 & $15.29 \pm 6.08$ & $11.22 \pm 5.72$ & 0.0036 \\
\hline Day 5 & $14.46 \pm 7.30$ & $9.61 \pm 5.61$ & 0.0029 \\
\hline Maximum & $17.07 \pm 7.18$ & $12.97 \pm 5.96$ & 0.0071 \\
\hline \multicolumn{4}{|c|}{ Maximum BT of the day $\left({ }^{\circ} \mathrm{C}\right)$} \\
\hline Day 1 & $36.9 \pm 0.7$ & $36.5 \pm 0.7$ & 0.0261 \\
\hline Day 2 & $37.6 \pm 0.6$ & $37.5 \pm 0.5$ & 0.3582 \\
\hline Day 3 & $37.7 \pm 0.5$ & $37.5 \pm 0.6$ & 0.0852 \\
\hline Day 4 & $37.5 \pm 0.6$ & $37.4 \pm 0.6$ & 0.4398 \\
\hline Day 5 & $37.3 \pm 0.4$ & $37.4 \pm 0.8$ & 0.7006 \\
\hline Maximum & $37.9 \pm 0.5$ & $37.9 \pm 0.6$ & 0.8893 \\
\hline
\end{tabular}

Abbreviations: BT, body temperature; CRP, C-reactive protein; Day X, Xth hospital day; OI, oxygenation impairment; WBC, white blood cell.

cutoff score determined by the ROC curve was set as 2 or greater (sensitivity: $89.7 \%$, specificity: $62.5 \%$, positive predictive value: $70.0 \%$, and negative predictive value: $86.2 \%$ ).

\section{Discussion}

\section{Oxygenation Impairment in Type-B AAD}

The incidence of $\mathrm{OI}$ in patients with distal AAD (type-B AAD) has been reported to be 39 to $51 \%,{ }^{7,8,10}$ and the same results were obtained in our study (39 of 79 type-B AAD, 49.4\%). Pathological studies have shown that inflammatory changes in the aortic wall occur during the course of AAD. ${ }^{18,19}$ In addition, Piantadosi and Schwartz reported that activated neutrophils release toxic mediators that destroy the pulmonary capillary endothelium and increase vascular permeability, thereby leading to alveolar fluid accumulation that causes respiratory failure. ${ }^{20}$ Recently, Furusawa et al reported that inhibiting the activity of neutrophil elastase may attenuate

Table 3 Factors (on admission day) associated with oxygenation impairment

\begin{tabular}{|l|l|l|l|l|}
\hline & Total & Ol group & Non-Ol group & \multirow{2}{*}{$p$ value } \\
\cline { 2 - 4 } & $\boldsymbol{n}=\mathbf{7 9}$ & $\boldsymbol{n}=39$ & $\boldsymbol{n}=\mathbf{4 0}$ & \\
\hline Age $<68$ years & $37(46.8)$ & $25(64.1)$ & $12(30.0)$ & 0.0024 \\
\hline Male gender & $52(65.8)$ & $30(76.9)$ & $22(55.0)$ & 0.0400 \\
\hline Body mass index $\geq 22 \mathrm{~kg} / \mathrm{m}^{2}$ & $57(72.2)$ & $36(92.3)$ & $21(52.5)$ & $<0.0001$ \\
\hline Maximum BT on admission day $>36.5^{\circ} \mathrm{C}$ & $47(59.5)$ & $29(74.4)$ & $18(45.0)$ & 0.0079 \\
\hline DeBakey IIIb & $66(83.5)$ & $36(92.3)$ & $30(75.0)$ & 0.0381 \\
\hline Patent or partial thrombosed false lumen & $32(40.5)$ & $21(53.8)$ & $11(27.5)$ & 0.0171 \\
\hline $\mathrm{PO}_{2} / \mathrm{FlO}_{2}$ on admission $<300$ & $41(51.9)$ & $31(79.5)$ & $10(25.0)$ & $<0.0001$ \\
\hline
\end{tabular}

Abbreviations: BT, body temperature; OI, oxygenation impairment.

Note: Number of cases in percentages. 
Table 4 Multivariate analysis of factors associated with oxygenation impairment

\begin{tabular}{|l|l|l|l|}
\hline & $p$ value & Odd ratio & 95\% confidence interval \\
\hline Age $<68$ years & 0.1255 & 2.9447 & $0.7396-11.7241$ \\
\hline Male gender & 0.6692 & 0.7321 & $0.1751-3.0605$ \\
\hline Body mass index $\geq 22 \mathrm{~kg} / \mathrm{m}^{2}$ & 0.0194 & 7.4885 & $1.3841-40.5148$ \\
\hline Maximum BT on admission day $>36.5^{\circ} \mathrm{C}$ & 0.0123 & 5.7438 & $1.4621-22.5648$ \\
\hline DeBakey IIIb & 0.2295 & 3.0863 & $0.4911-19.3946$ \\
\hline Patent or partial thrombosed false lumen $_{\mathrm{PO}_{2} / \mathrm{FIO}_{2} \text { on admission }<300} \mathrm{0.0847}$ & 3.4216 & $0.8451-13.8529$ \\
\hline
\end{tabular}

Abbreviation: BT, body temperature.

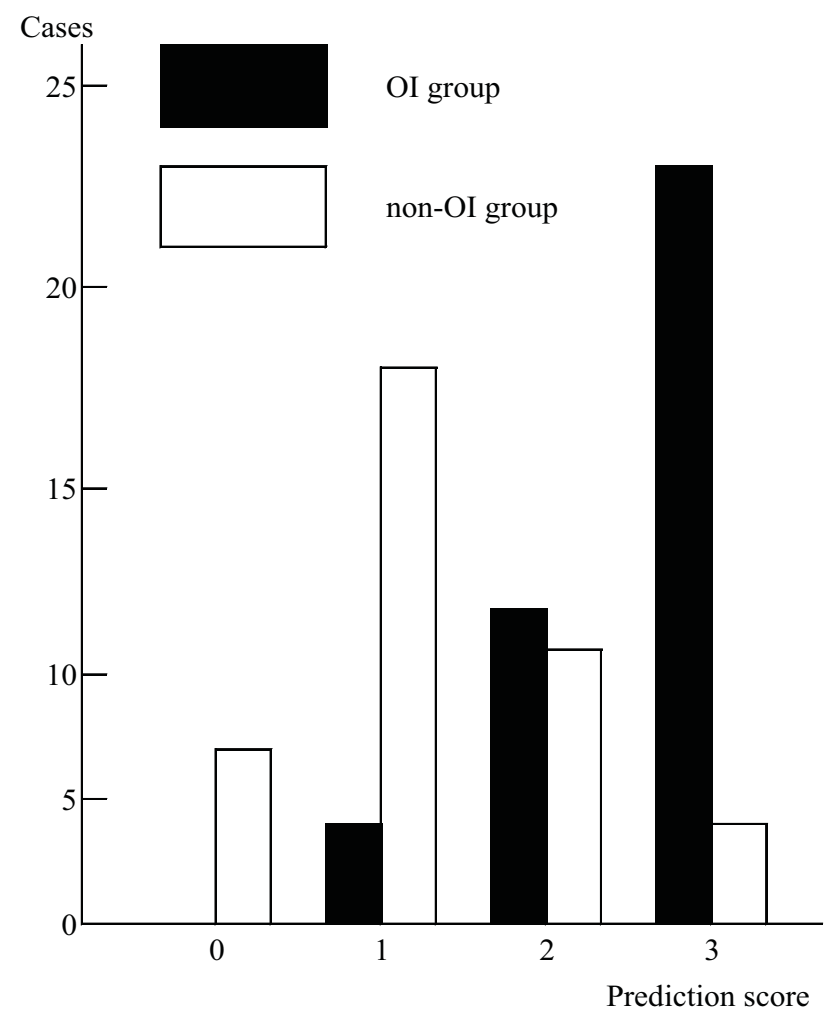

\begin{tabular}{lcc}
\hline & OI group & non-OI group \\
\hline Prediction score $\geq 2$ & 35 & 15 \\
Prediction score $\leq 1$ & 4 & 25 \\
\hline
\end{tabular}

$\begin{array}{rrr}\text { sensitivity } & 89.7 \% & (35 / 39) \\ \text { specificity } & 62.5 \% & (25 / 40) \\ \text { positive predictive value } & 70.0 \% & (35 / 50) \\ \text { negative predictive value } & 86.2 \% & (25 / 29)\end{array}$

Fig. 2 Predicting the occurrence of $\mathrm{Ol}$ in patients with type-B acute aortic dissection. The applicable number of three factors associated with Ol (body mass index $\geq 22 \mathrm{~kg} / \mathrm{m}^{2}$, maximum body temperature on the admission day $>36.5^{\circ} \mathrm{C}$, and $\mathrm{Po}_{2} / \mathrm{FlO}_{2}$ ratio on admission $<300$ ) was defined as the prediction score. This score was able to predict the occurrence of OI when the cutoff value was set at point 2 or greater. OI, oxygenation impairment. postoperative respiratory complications in patients with AAD. ${ }^{21}$ In addition, it has been reported that pleural effusion frequently occurs in patients with $\mathrm{AAD}$, often in association with inflammatory reactions, including high body temperatures and increased WBC counts and serum CRP levels. ${ }^{22}$ The occurrence of $\mathrm{OI}$ has been reported to be strongly associated with active inflammatory reactions, including high WBC counts, serum CRP levels, and body temperatures. ${ }^{7,8,10}$ These active inflammatory reactions were also demonstrated in the present study.

Kurabayashi et al found that respiratory failure in AAD patients appears to be closely correlated with the degree of aortic injury measured on precise evaluation of CT films, possibly mediated by the magnitude of the systemic inflammatory reaction to the aortic injury. ${ }^{10}$ Our results also showed that OI occurred more frequently in the patients with larger aortic dissections (DeBakey IIIb) than those with DeBakey IIla aortic dissections.

During this decade, sleep apnea syndrome has been reported to be a risk factor for the development of cardiovascular diseases, including AAD. ${ }^{23-29}$ In addition, sleep apnea is frequently observed in obese patients. ${ }^{30-34}$ Therefore, we suggest that high body mass indices may be associated with the occurrence of OI based on the results of this study. However, the relationship between sleep apnea and OI was not investigated in this retrospective study.

\section{Clinical Factors Affecting Oxygenation Impairment}

In this study, the peak levels of serum CRP and WBC count were associated with the occurrence of $\mathrm{OI}$ in type-B AAD patients. These findings have been reported previously, and higher levels of serum CRP after distal type AAD are associated with a higher incidence of $\mathrm{OI}$ and poor clinical outcomes in patients with aortic and peripheral artery diseases. ${ }^{7,8,11-13}$ Systemic activation of the inflammatory system after aortic injury may play an important role in the development of OI. Although previous reports have found that the peak values of WBC counts, serum CRP levels, and body temperature are associated with OI, these values are inappropriate for predicting the occurrence of OI because they were measured after the occurrence of $\mathrm{OI}$.

Except for the presence of inflammatory reactions, factors regarding patient backgrounds, including younger age, male gender, and nonslender frame, were associated with the 
occurrence of $\mathrm{OI}$ in this study. We were unable to evaluate sleep apnea, though there may be a relationship between obesity, sleep apnea, and OI in AAD patients.

\section{Predicting the Occurrence of Oxygenation Impairment} Although factors affecting OI such as WBC count, CRP levels, and body temperature have been previously reported, ${ }^{7,8,11-13}$ the possibility of predicting the occurrence of OI has not yet been investigated. Therefore, we evaluated this relationship using factors measured before the occurrence of $\mathrm{OI}$ in type-B AAD patients. In the present study, OI occurred on hospital day 2.5 in the AAD patients, and we investigated factors measured on the admission day. In this study, we adopted the following factors for predicting the occurrence of OI: age, gender, body mass index, maximum body temperature on the admission day, type of AAD (the presence of a patent false lumen and DeBakey IIla or IIIb), and $\mathrm{P} / \mathrm{F}$ ratio on admission. The serum levels of CRP and WBC count were not used because increases in these levels were observed after the occurrence of OI. In addition, the multivariate analysis revealed that nonslender frame, relatively high maximum body temperature on the admission day, and lower $\mathrm{P} / \mathrm{F}$ ratio on admission were more strongly associated with the occurrence of OI than the other factors.

To predict the occurrence of $\mathrm{OI}$ in type-B AAD patients, predictive scores were calculated according to the number of the following three applicable factors: nonslender frame $\left(\mathrm{BMI} \geq 22 \mathrm{~kg} / \mathrm{m}^{2}\right)$, relatively high maximum body temperature on the admission day $\left(>36.5^{\circ} \mathrm{C}\right)$, and a lower $\mathrm{P} / \mathrm{F}$ ratio on the admission day $(<300)$. When the cutoff values were set at point 2 or greater, the scores were able to predict the occurrence of $\mathrm{OI}$ in type-B AAD patients with a high predictive value. We state here that this scoring system for predicting the occurrence of OI could be made available in the clinical setting of almost every institute.

\section{Study Limitations}

First, this study was conducted at only one university hospital, and the number of cases was small. Second, there was a lack of precise data regarding coagulation findings including D-dimer due to the retrospective design. Last, we were not able to evaluate the presence of sleep apnea in individual cases. Therefore, conducting a large cohort study is recommended to address these problems.

\section{Acknowledgments}

The authors thank the staff of the intensive care unit and hospital, especially the critical care center, for the management of the patients. We also thank the staff of the medical records office for their valuable assistance.

\section{References}

1 Daily PO, Trueblood HW, Stinson EB, Wuerflein RD, Shumway NE. Management of acute aortic dissections. Ann Thorac Surg 1970;10 (3):237-247

2 Khan IA, Nair CK. Clinical, diagnostic, and management perspectives of aortic dissection. Chest 2002;122(1):311-328
3 Elefteriades JA, Lovoulos CJ, Coady MA, Tellides G, Kopf GS, Rizzo JA. Management of descending aortic dissection. Ann Thorac Surg 1999;67(6):2002-2005, discussion 2014-2019

4 Neya K, Omoto R, Kyo S, et al. Outcome of Stanford type B acute aortic dissection. Circulation 1992;86(5, Suppl):II1-II7

5 Hasegawa Y, Ishikawa S, Ohtaki A, et al. Impaired lung oxygenation in acute aortic dissection. J Cardiovasc Surg (Torino) 1999;40(2): 191-195

6 Neri E, Sassi C, Massetti M, et al. Nonocclusive intestinal ischemia in patients with acute aortic dissection. J Vasc Surg 2002;36 (4):738-745

7 Sugano Y, Anzai T, Yoshikawa T, et al. Serum C-reactive protein elevation predicts poor clinical outcome in patients with distal type acute aortic dissection: association with the occurrence of oxygenation impairment. Int J Cardiol 2005;102(1):39-45

8 Komukai K, Shibata T, Mochizuki S. C-reactive protein is related to impaired oxygenation in patients with acute aortic dissection. Int Heart J 2005;46(5):795-799

9 Jo Y, Anzai T, Sugano Y, et al. Early use of beta-blockers attenuates systemic inflammatory response and lung oxygenation impairment after distal type acute aortic dissection. Heart Vessels 2008;23(5):334-340

10 Kurabayashi M, Okishige K, Azegami K, et al. Reduction of the PaO2/ FiO2 ratio in acute aortic dissection - relationship between the extent of dissection and inflammation -. Circ J 2010;74(10): 2066-2073

11 Liuzzo G, Biasucci LM, Gallimore JR, et al. The prognostic value of Creactive protein and serum amyloid a protein in severe unstable angina. N Engl J Med 1994;331(7):417-424

12 Ridker PM, Cushman M, Stampfer MJ, Tracy RP, Hennekens CH. Plasma concentration of C-reactive protein and risk of developing peripheral vascular disease. Circulation 1998;97(5):425-428

13 Domanovits $H$, Schillinger $M$, Müllner $M$, et al. Acute phase reactants in patients with abdominal aortic aneurysm. Atherosclerosis 2002;163(2):297-302

14 Shapiro BA, Kacmarek RM, Cane RD, Peruzzi WT, Hauptonman D. Oxygen Therapy. In: Clinical Application of Respiratory Care, 4th ed. St. Louis: Mosby; 1991:123-134

15 Bernard GR, Artigas A, Brigham KL, et al. The American-European Consensus Conference on ARDS. Definitions, mechanisms, relevant outcomes, and clinical trial coordination. Am J Respir Crit Care Med 1994;149(3 Pt 1):818-824

16 DeBakey ME, McCollum CH, Crawford ES, et al. Dissection and dissecting aneurysms of the aorta: twenty-year follow-up of five hundred twenty-seven patients treated surgically. Surgery 1982; 92(6):1118-1134

17 Tsai TT, Evangelista A, Nienaber CA, et al; International Registry of Acute Aortic Dissection. Partial thrombosis of the false lumen in patients with acute type B aortic dissection. N Engl J Med 2007;357 (4):349-359

18 Ishii T, Asuwa N. Collagen and elastin degradation by matrix metalloproteinases and tissue inhibitors of matrix metalloproteinase in aortic dissection. Hum Pathol 2000;31(6):640-646

19 Müller BT, Modlich O, Prisack HB, et al. Gene expression profiles in the acutely dissected human aorta. Eur J Vasc Endovasc Surg 2002;24(4):356-364

20 Piantadosi CA, Schwartz DA. The acute respiratory distress syndrome. Ann Intern Med 2004;141(6):460-470

21 Furusawa T, Tsukioka K, Fukui D, et al. The effects of a neutrophil elastase inhibitor on the postoperative respiratory failure of acute aortic dissection. Thorac Cardiovasc Surg 2006;54(6):404-407

22 Hata N, Tanaka K, Imaizumi T, et al. Clinical significance of pleural effusion in acute aortic dissection. Chest 2002;121(3):825-830

23 Bradley TD, Floras JS. Obstructive sleep apnoea and its cardiovascular consequences. Lancet 2009;373(9657):82-93

24 Yamashita S, Dohi T, Narui K, Momomura S. Therapeutic efficacy of continuous positive airway pressure in obstructive sleep apnea patients with acute aortic dissection: a case report. J Atheroscler Thromb 2010;17(9):999-1002 
25 Inami T, Seino Y, Mizuno K. Untreated severe obstructive sleep apnoea and development of acute aortic dissection. BMJ Case Rep 2012 (e-pub ahead of print). doi:10.1136/bcr-02.2012-5741

26 Sampol G, Romero O, Salas A, et al. Obstructive sleep apnea and thoracic aorta dissection. Am J Respir Crit Care Med 2003;168 (12):1528-1531

27 Saruhara H, Takata Y, Usui Y, et al. Obstructive sleep apnea as a potential risk factor for aortic disease. Heart Vessels 2012;27 (2):166-173

28 Hata M, Yoshitake I, Wakui S, et al. Sleep disorders and aortic dissection in a working population. Surg Today 2012;42 (4):403-405

29 Yoshimura C, Oga T, Chin K, et al. Relationships of decreased lung function with metabolic syndrome and obstructive sleep apnea in Japanese males. Intern Med 2012;51(17):2291-2297
30 de Sousa AG, Cercato C, Mancini MC, Halpern A. Obesity and obstructive sleep apnea-hypopnea syndrome. Obes Rev 2008;9 (4):340-354

31 Daltro C, Gregorio PB, Alves E, et al. Prevalence and severity of sleep apnea in a group of morbidly obese patients. Obes Surg 2007;17(6):809-814

32 Palla A, Digiorgio M, Carpenè N, et al. Sleep apnea in morbidly obese patients: prevalence and clinical predictivity. Respiration 2009;78(2):134-140

33 Valencia-Flores M, Orea A, Castaño VA, et al. Prevalence of sleep apnea and electrocardiographic disturbances in morbidly obese patients. Obes Res 2000;8(3):262-269

34 Wall H, Smith C, Hubbard R. Body mass index and obstructive sleep apnoea in the UK: a cross-sectional study of the over-50s. Prim Care Respir J 2012;21(4):371-376 